\title{
POTENCIAL ANTIOXIDANTE DA FICOCIANINA NA LEVEDURA Saccharomyces cerevisiae MUTANTES AO GENE Sir
}

\author{
M. BALEN ${ }^{1}$, C. SILVEIRA ${ }^{1}$, F. BENETTI ${ }^{2}$, B. SEGUENKA ${ }^{2}$, G. NICOLETTI ${ }^{1}$, W. F. \\ MARTINS $^{1}$ A. C. V. SALLA ${ }^{2}$, F. S. N. MELO e T. E. BERTOLIN ${ }^{2}$ \\ ${ }^{1}$ Universidade Federal de Santa Catarina, Departamento de Engenharia Química e \\ Engenharia de Alimentos \\ ${ }^{2}$ Universidade de Passo Fundo, Faculdade de Engenharia, Curso de Engenharia de \\ Alimentos \\ ${ }^{3}$ Universidade Federal da Paraíba, Centro de Tecnologia \\ E-mail para contato: balenmanuela@gmail.com
}

RESUMO - Compostos antioxidantes apresentam capacidades funcionais que podem proporcionar o prolongamento da vida pela atenuação do estresse oxidativo. Em vista disto, objetivou-se verificar a ação protetora da ficocianina na viabilidade celular da Saccharomyces cerevisiae mutantes ao gene sir. Utilizou-se cepas de leveduras Saccharomyces cerevisiae controle (BY4741) e deletadas aos genes sir1, sir2, sir3 e sir4. As células foram crescidas em meio YPD $2 \%$. As cepas foram submetidas a $24 \mathrm{~h}$ de envelhecimento e coletadas para as análises de sobrevivência celular. O percentual de sobrevivência foi aumentado frente ao tratamento com ficocianina nas cepas deletadas ao gene sir1, sir2 e sir4 e na cepa controle. A deleção do gene sir3, foi a que apresentou menor influência no percentual de sobrevivência frente ao tratamento com ficocianina. A cepa deletada ao gene sir2 foi a que melhor reconheceu o tratamento com ficocianina. $O$ tratamento com ficocianina mostrou benefício na viabilidade celular.

\section{INTRODUÇÃO}

Recentes evidências sugerem que o uso de substâncias naturais como a de diferentes compostos fenólicos, apresentam capacidades funcionais que podem proporcionar o aumento da vida pela atenuação do estresse oxidativo, inibição da incidência de patologias relativas a idade, aumento da imunidade e diminuição de processos inflamatórios. Dentre estas substâncias, o resveratrol tem sido investigado em diferentes modelos experimentais com estes objetivos. Os estudos de outras moléculas potenciais tornam-se, por estes motivos de grande importância para a potencialização destas pesquisas. Um antioxidante em potencial deve eliminar radicais livres especificamente, quelar metais; interagir com outros antioxidantes, ter um efeito positivo na expressão gênica, ser completamente absorvido, ter uma concentração relevante em tecidos e biofluidos e agir em ambos ambientes (Silva, 2007).

Os antioxidantes são substâncias utilizadas na preservação dos alimentos, pois retardam a sua deterioração, rancidez e descoloração que são decorrentes do processo de oxidação. O interesse pelos antioxidantes naturais teve início nos anos 80 (Soares, Andreazza e Salvador, 2005; Coneglian et al., 2011). Estas substâncias podem atuar no processo de preservação de várias formas, incluindo a complexação de íons metálicos, sequestro de radiais livres e decomposição de peróxidos (Coneglian et al., 2011). 
A Spirulina é uma cianobactéria que habita meios diversos como solos, areias, pântanos, lagos alcalinos e águas salobras, marinhas e doces. Por meio da fotossíntese, converte os nutrientes em matéria celular e libera oxigênio. Os primeiros relatos do uso da Spirulina na alimentação datam da pré-história, a partir da informação de que tribos de caçadores coletavam massas gelatinosas de algas verde-azuladas e as consumiam cruas ou cozidas. Para enriquecer suas dietas, também consumiam algas filamentosas coletadas em lagos alcalinos, as quais são conhecidas como sendo do gênero Spirulina (Richmond, 1990; Andrade e Costa, 2008).

A Spirulina platensis é legalmente autorizada como alimento ou complemento alimentar na Europa, Japão e Estados Unidos pelo FDA, que recentemente, emitiu o primeiro certificado Generally Recognized as Safe (GRAS) para a Spirulina, deliberando o seu uso como alimento sem apresentar risco à saúde. No Brasil, a Agência Nacional de Vigilância Sanitária (ANVISA) reconheceu a Spirulina como ingrediente que pode ser utilizado nas formulações de alimentos, sendo que a recomendação diária de consumo do produto deve ser limitada a 1,6 g (Von Der Weid et al., 2000).

As cianobactérias têm recebido atenção especial devido à presença de pigmentos, dentre eles, carotenóides, clorofila e biliproteinas, os quais conferem diferentes propriedades funcionais. A Spirulina platensis tem como seu principal pigmento a ficobiliproteína, ficocianina. Para tal, esta microalga apresenta-se como estimulante ao sistema imunológico. Em muitos países, o pigmento é usado como suplemento alimentar, devido ao seu potencial nutracêutico, anti-inflamatório, antibacteriano, no perfil lipídico, neuroprotetor e anti-estressor, observados em diferentes modelos experimentais, na prevenção de certos tipos de cânceres, antioxidante (Von Der Weid et al., 2000; Bertolin et al., 2009;).

A ficocianina principal componente do extrato aquoso de Spirulina platensis, possui características importantes como: ser uma proteína natural, de cor azul única, boa solubilidade em água, alta estabilidade na faixa de $\mathrm{pH}$ 5-7, fluorescência e propriedades terapêuticas, com atividades antioxidante e anti-inflamatória com uma promissora aplicação em diagnósticos, pois o purificado possui propriedades fluorescentes que possibilita a utilização em ensaios imunológicos (Deng e Chow, 2010).

Por ser um pigmento natural, pode ser utilizado na indústria de alimentos, como corante, por exemplo, em sucos e gomas e na indústria de cosméticos, substituindo os corantes sintéticos (Chu et al., 2010).

O uso de modelos experimentais torna-se importante para a universalização de conhecimentos relativos ao prologamento da vida. As células de levedura Saccharomyces cerevisiae são utilizadas em larga escala para estudos dos fenômenos da bioquímica, biologia celular e molecular, caracterizando-se como um dos melhores modelos de sistema eucariótico unicelular para tais estudos. Seu metabolismo é semelhante ao de eucariotos superiores, com mecanismos próprios de ativação metabólica e de detoxificação. Apesar das diferenças de complexidade entre leveduras e humanos, o estudo do envelhecimento em leveduras tem mostrado informações importantes em vias que modulam o processo do envelhecimento em mamíferos (Mannarino et al., 2008).

Outro fator que colabora para que estes microrganismos sejam uma ótima escolha de modelo experimental para estudos da resposta celular, é a facilidade de obtenção de cepas mutantes através de técnicas de genética clássica e molecular. Em adição, o seu pequeno tempo de geração quando comparado com as células animais e o seu genoma 
completamente mapeado. Por estas razões, a levedura Saccharomyces cerevisiae caracteriza-se como um dos melhores modelos de sistema eucariótico unicelular para estudos de estresse oxidativo (Mannarino et al., 2008).

Neste contexto, objetiva-se avaliar o potencial antioxidante e ativador do gene Sir através do pigmento ficocianina em células de levedura Saccharomyces cerevisiae deletadas ou não ao gene Sir.

\section{MATERIAL E MÉTODOS}

\subsection{Antioxidante}

O composto antioxidante analisado foi a ficocianina principal pigmento da microalga Spirulina platensis.

\subsection{Modelo experimental}

A levedura Saccharomyces cerevisiae deletada ao gene $\operatorname{sir} 1 \Delta, \operatorname{sir} 2 \Delta, \operatorname{sir} 3 \Delta$ e sir4 $\Delta$ e controle foram obtidas da Euroscarf, Frankfurt, Germany. O Quadro 1 apresenta as linhagens que serão utilizadas nos experimentos.

As linhagens de levedura Saccharomyces cerevisiae foram mantidas em meio YPD sob refrigeração a $4{ }^{\circ} \mathrm{C}$, como apresentado no Quadro 1 . A manutenção dos microorganismos foi realizada através de repiques periódicos em meio YPD. No caso das cepas mutantes $\operatorname{sir} 1 \Delta$, $\operatorname{sir} 2 \Delta$, $\operatorname{sir} 3 \Delta$ e $\operatorname{sir} 4 \Delta$, o meio de cultura será acrescido de $0,02 \%$ de geneticina. As culturas serão mantidas a $4^{\circ} \mathrm{C}$ em ágar inclinado (cultura estoque).

\subsection{Condições de cultivo}

As células, retiradas de um repique fresco em meio sólido YPD $2 \%$, foram cultivadas em erlenmeyers, contendo $20 \%$ do seu volume preenchido por meio YPD 2 $\%$. Após a realização do inóculo, as culturas foram incubadas a $28{ }^{\circ} \mathrm{C} \mathrm{em}$ agitador orbital ajustado para $160 \mathrm{rpm}$ até a primeira fase exponencial de crescimento (entre 0,5 e $0,9 \mathrm{mg}$ de peso seco de células $/ \mathrm{mL}$ ). Nesta fase, as células crescidas em YPD $2 \%$ apresentam um metabolismo fermentativo, utilizando a glicose presente no meio como única fonte de carbono e não dependendo do oxigênio como aceptor final dos elétrons.

\subsection{Viabilidade celular}

A viabilidade celular foi analisada em meio sólido YPD $2 \%$ antes e após envelhecimento (Eleutherio et al., 1995). As placas foram incubadas a $28{ }^{\circ} \mathrm{C}$ por $72 \mathrm{~h}$ e o número de colônias contado. O percentual de sobrevivência foi determinado de acordo com Eleutherio et al. (1995).

\section{RESULTADOS E DISCUSSÃO}

A longevidade celular foi verificada através do percentual de células viáveis (percentual de sobrevivência) após o processo de envelhecimento. A Tabela 1 apresenta as médias \pm desvio padrão do percentual de sobrevivência para os diferentes tratamentos nas cepas de leveduras Saccharomyces cerevisiae. 
Tabela 1 - Valores médios do percentual de sobrevivência (\%) para os diferentes tratamentos na Saccharomyces cerevisiae em 24 h de envelhecimento

\begin{tabular}{cc}
\hline Tratamentos & $\mathbf{2 \%}$ glicose \\
\hline Controle & $14,61 \pm 2,81$ \\
Controle + FC* & $24,19 \pm 3,05$ \\
sir 1 & $27,93 \pm 0,54$ \\
sir $1+\mathrm{FC}^{*}$ & $33,29 \pm 1,43$ \\
sir2 & $32,62 \pm 2,62$ \\
sir2 $+\mathrm{FC}^{*}$ & $64,34 \pm 4,62$ \\
sir3 & $40,23 \pm 1,21$ \\
sir3 $+\mathrm{FC}^{*}$ & $42,31 \pm 6,42$ \\
sir4 & $21,78 \pm 8,31$ \\
sir4 $+\mathrm{FC}^{*}$ & $30,35 \pm 9,03$ \\
\hline
\end{tabular}

Os resultados apresentados na Tabela 1 mostram que o percentual de sobrevivência foi superior nas cepas deletadas aos genes $\operatorname{sir} 1, \operatorname{sir} 2$, sir3 e $\operatorname{sir} 4$ em relação à cepa controle. Essa superioridade foi estatisticamente significativa apenas para as cepas deletadas aos genes sir2 e sir3.

No cultivo de células em $2 \%$ de glicose acrescidas de ficocianina $(P+F C)$, observa-se que o percentual de sobrevivência também foi superior nas cepas deletadas para os genes sir1, sir2, sir3 e sir4 em relação à cepa controle. Diferenças estatísticas foram observadas apenas nas cepas deletadas aos genes $\operatorname{sir} 2(\mathrm{p}=0,000)(\mathrm{p}<0,05) \mathrm{e}$ $\operatorname{sir} 3(\mathrm{p}=0,010)(\mathrm{p}<0,05)($ Tabela 4$)$.

Quando analisamos cada cepa de forma individual, nos cultivos $2 \%$ de glicose + ficocianina $(\mathrm{P}+\mathrm{FC})$ e $2 \%$ glicose $(\mathrm{P})$, verificamos que o resultado mostrou que no envelhecimento de $24 \mathrm{~h}$, todas as cepas cultivadas no tratamento $2 \%$ de glicose + ficocianina $(\mathrm{P}+\mathrm{FC})$, mostraram percentual de sobrevivência superior aos do cultivo com $2 \%$ glicose $(\mathrm{P})$. Nesta comparação, foram encontradas diferenças significativas apenas para a cepa deletada para o gene sir2.

O percentual de sobrevivência foi aumentado frente ao tratamento com ficocianina nas cepas deletadas ao gene $\operatorname{sir} 1$, sir 2 e $\operatorname{sir} 4$ e na cepa controle. Foi possível observar que a deleção do gene sir3, foi a que apresentou menor influência no percentual de sobrevivência frente ao tratamento com ficocianina. Este comportamento 
não apresentou diferenças estatísticas. Os resultados mostraram que, no processo de envelhecimento, as cepas tiveram maior sobrevivência quando expostas à ficocianina em relação às não expostas.

O estudo de Bescós, Estrada e Fresno (2008), analisou os componentes antioxidantes da Spirulina platensis, concluindo que a ficocianina é o principal componente responsável pela defesa antioxidante das células. Em outra pesquisa, os mesmos autores, estudaram células de neuroblastoma humano. $\mathrm{O}$ estudo teve como objetivo estudar a possibilidade da ficocianina ser um agente de proteção da toxicidade, atuando na prevenção e/ou tratamento de doenças degenerativas. No estudo, o estresse oxidativo foi induzido pelo Ferro $\left(\mathrm{Fe}^{2}+\right)$. As células quando expostas ao extrato protéico, foram capazes de reduzir os efeitos induzidos com $\mathrm{Fe}^{2}+$, aumentando significativamente os níveis celulares das enzimas com atividade antioxidante incluindo glutationa peroxidase (GPX), glutationa selênio-dependente (GPX-Se) e glutationa oxidase redutase (GR) (GSH, GR, GPx) (Bescós, Estrada e Fresno, 2008).

A literatura mostra que a Spirulina e seus pigmentos antioxidantes podem prevenir ou inibir o câncer em seres humanos ou animais. Os estudos in vitro sugerem que os polissacarídeos da Spirulina aumentam a atividade enzimática do núcleo da célula e reparo na síntese do DNA (Pang et al., 1998; Bescós, Estrada e Fresno 2008).

\section{CONCLUSÃO}

O uso da terapia com ficocianina mostrou benefício no percentual de sobrevivência celular do modelo levedura Saccharomyces cerevisiae.

\section{REFERÊNCIAS}

ANDRADE, M. R.; COSTA, J. A. V. Cultivo da microalga spirulina platensis em fontes alternativas de nutrientes. Ciência e agrotecnologia, v. 32, n. 5, 2008.

BERTOLIN, T. E. et al. Effect of microalga Spirulina platensis (Arthrospira platensis) on hippocampus lipoperoxidation and lipid profile in rats with induced hypercholesterolemia. Brazilian Archives of Biology and Technology, v. 52, p. 12531259, 2009.

BESCÓS, P. B.; ESTRADA, E. P.; FRESNO, A. M. V. Neuroprotection by Spirulina platensis protean extract and phycocyanin against iron-induced toxicity in SH-SY5Y neuroblastoma cells. Toxicology in Vitro, v. 22, n. 6, p. 1496-1502, 2008.

CHU, W.L., et al. Protective effect of aqueous extract from Spirulina platensis against cell death induced by free radicals. Complementary and Alternative Medicine, v.10, n.53, p.2-8, 2010.

CONEGLIAN, S. M. et al. Utilização de antioxidantes nas rações. Publicações em Medicina Veterinária e Zootecnia, Londrina, v. 5, n. 5, p. 1-3, 2011.

DENG, R.; CHOW, T. J.; Hypolipidemic, Antioxidant, and Antiinflammatory Activities of Microalgae Spirulina. Cardiovascular Therapeutics, v. 28, p. 33-45, 2010. 
ELEUTHERIO, E. C. A. et al. Effect of trehalose during stress conditions in a heatshock resistant mutant of Saccharomyces cerevisiae. Biochemistry and Molecular Biology International, v. 36, p. 1217-1223,1995.

MANNARINO, S. C.; AMORIM, M. A.; PEREIRA, M. D.; FERREIRA M. P.; PANEK, A. D., COSTA, V., ELEUTHERIO, E. C. A. Glutathione is necessary to ensure benefits of caloric restriction during ageing in Saccharomyces cerevisiae. Mechanisms of Ageing and Development, v. 129, p. 700-705, 2008.

PANG, Q. S.; GUO, B. J.; RUAN, GUO, J. H. Enhancement of endonuclease activity and repair DNA synthesis by polysaccharide of Spirulina platensis. I Chuan Hsuch Pao, v. 15, p. 374-381, 1998.

RICHMOND, A. Handbook of Microalgal Mass Culture. Boston , v. 1, p. 346-413, ago.1990.

SILVA, C. G. Avaliação do potencial antioxidante de extratos de plantas brasileiras e da isoquercetina no modelo de células eucariótica, Saccharomyces cerevisae. Tese (Mestrado em Ciências-Bioquímica)-Universidade do Rio de Janeiro, Rio de Janeiro, 2007.

SOARES, D. G.; ANDREAZZA, A. C.; SALVADOR, M., Avaliação de compostos antioxidantes em células da levedura Saccharomyces cerevisiae. Revista Brasileira de Ciências Farmacêuticas,São Paulo,v.41, n.1, jan./mar. 2005.

VON DER WEID, D.; DILLON, J. C.; FALQUET, J. Malnutrition: a silent massacre. Geneve. Antenna Technology, p. 13, 2000. 